\begin{tabular}{ll}
\hline \hline MINING AND METALLURGY INSTITUTE BOR & ISSN: 2334-8836 (Štampano izdanje) \\
UDK: 622 & ISSN: 2406-1395 (Online) \\
\hline \hline
\end{tabular}

UDK: 669:681.5(045)=111

doi:10.5937/mmeb1804033R

Srbislav Radivojević, Mlađan Maksimović, Darjan Karabašević, Srđan Novaković*

\title{
SELECTION OF PRODUCTION LINES IN \\ THE METALLURGICAL INDUSTRY USING THE COMPROMISE PROGRAMMING METHOD
}

\begin{abstract}
Every organization today faces the problem of decision making. In this regard, the intent of this paper is to present an approach based on the multi-criteria decision-making methods. Primarily, the proposed approach is aimed to help solving problem of choosing the optimal production lines in the metallurgical industry. The proposed approach is based on the use of the AHP method for determining the weights of criteria, whereas the Compromise Programming is used for selection the alternatives. The usability, applicability and efficiency of the proposed approach is demonstrated in a conducted case study of selection the production lines in the metallurgical industry.
\end{abstract}

Keywords: metallurgical industry; production lines; MCDM; Compromise Programming

\section{INTRODUCTION}

Metallurgy represents a science that is aimed to the production of metal alloys. Most often it includes the refining, alloy production, shaping and refining, as well as studying the structure, composition and properties of metals. By a type of metal, it is most often divided into the ferrous (iron and steel) and metallurgy of non-ferrous metals (obtaining all other metals). Legrand et al. [1] states that the "metallurgical industry mainly transforms steel or its derivative products into products with either better surface properties (thanks to the surface transformations....), or into different shape products (lamination...), involves some processing tools which can generate the flaws (cracks, grooves...) within the process".

Until now, the multiple-criteria decisionmaking (MCDM) is often used as a tool for solving a wide range of complex problems. In the simplest sense, the MCDM can be defined as the selection of an alternative from the set of available alternatives [2]. Also, very rapid development of the MCDM field has caused a creation of many MCDM methods, such as: SAW, AHP, PROMETHEE, ELECTREE, COPRAS, MOORA, ARAS and MULTIMOORA, etc. Comparisons of some of them are given by Mardani et al. [3] and Turskis and Zavadskas [4]. So far, MCDM methods have been successfully applied in solving problems in the metallurgical industry such as: thermoplastic matrix selection for fiber metal laminate using the fuzzy VIKOR and entropy measure for objective weighting [5] and selecting the Complementary Metal Oxide Semiconductor (CMOS) Image Sensors using a fuzzy MCDM framework [6].

Based on the above stated, the main aim of the paper is to provide the effective approach based on the MCDM methods for

\footnotetext{
* Faculty of Applied Management, Economics and Finance, University Business Academy in Novi Sad, Jevrejska 24, 11000 Belgrade, Serbia.E-mail: darjan.karabasevic@mef.edu.rs
} 
selection the production lines in the metallurgical industry. The AHP method is applied for the weight determination whereas the programming is applied for ranking the alternative compromise.

Therefore, the paper is organized as follows. In Section 1, the Introductory considerations are presented. In section 2, the applied methodology is explained. In section 3, the conducted case study is presented. Finally, the conclusions are given at the end of manuscript.

\section{METHODOLOGY}

The Method of Analytical Hierarchical Processes (AHP), which is proposed by Saaty [7] is one of the most popular methods of multi-criteria decision making. The popularity of this method is influenced by the hierarchical problem structuring and comparison in pairs. Therefore, the AHP method was applied for determining the weight of criteria.

The concept of Compromise Programming (CP) was proposed by $\mathrm{Yu}$ [8] and Zeleny [9]. Until now, the CP was applied in order to solve different problems, such as: Fuzzy-based heat and power hub models for the cost-emission operation of an industrial consumer using compromise programming [10], a Nadir Compromise Programming for supplier selection problem under uncertainty [11], empowering cash managers through Compromise Programming [12], etc.

The basic idea of the CP is to determine the alternative that has the least distance from the ideal solution (ideal point).

For some problems of multi-criteria decision-making that involves $m$ alternatives that are evaluated on the basis of $n$ criteria, the procedure for selecting the most acceptable alternative can be represented as follows:

$$
\min L_{p, i}=\left\{\sum_{j=1}^{n} w_{j}^{p}\left(\frac{x_{j}^{*}-x_{i j}}{x_{j}^{*}-x_{j}^{-}}\right)^{p}\right\}^{\frac{1}{p}}
$$

where $L_{p, i}$ is the distance metric of alternative $i$ for a given parameter $p ; w_{j}$ is the weight of criterion $j ; x_{i j}$ is the performance of alternative $i$ to criterion $j ; x_{j}^{*}$ and $x_{j}^{-}$ are the best and the worst performance of alternative $i$ for criterion $j, i=1,2, \ldots, m$; $m$ denotes number of alternatives, and $j=1,2, \ldots, n ; n$ denotes the number of criteria.

The parameter $p$, in equation (1), is used to represent the importance of maximal deviation from the ideal point. By varying the parameter $p$ from 1 to infinity, it is possible to move from minimizing sums of individual deviations to minimizing the maximal deviations to the ideal point, in a decision-making process. More precisely, when the parameter $\mathrm{p}$ has a value of 1 , all the distances in relation to the ideal point have the same significance and, in this case, the sum of distance in relation to each criterion is calculated, and alternative with the lowest sum value is the most acceptable. The choice of a particular value of this compensation parameter $p$ depends on the type of problem and desired solution [13].

The best $x_{j}^{*}$ and the worst $x_{j}^{-}$performance for criterion $j$ should be determined as follows:

$$
\begin{aligned}
& x_{j}^{*}=\left\{\begin{array}{ll}
\max _{i} x_{i j} ; & j \in \Omega_{\max } \\
\min _{i} x_{i j} ; & j \in \Omega_{\min }
\end{array},\right. \text { and } \\
& x_{j}^{-}= \begin{cases}\min _{i} x_{i j} ; & j \in \Omega_{\max } \\
\max _{i} x_{i j} ; & j \in \Omega_{\min }\end{cases}
\end{aligned}
$$

where $\Omega_{\max }$ and $\Omega_{\max }$ denote the set of benefit and cost criteria, respectively.

Determination of the most acceptable alternative with application of compromise programming method is considered to be relatively simple, but also efficient and understandable for decision makers. Accor- 
dingly, we suggest application of this method when solving problems of production lines in the metallurgical industry.

The evaluation of alternatives based on application of AHP and CP methods in the group environment will be presented below.

In a group environment, the decisions are made based on the views of several respondents, usually experts in the relevant field. In the literature, several approaches to a group decision-making have been considered, and as a commonly used procedure, it is possible to indicate the approach in which:

- determine the group weights of criteria based on the weights of criteria obtained from each respondent using the AHP method;

- determine the group performances of alternatives in relation to the criteria based on the performances of alternatives obtained from each respondent;

- determine the overall performances, i.e. the significance of each alternative of some MCDM method, and, in given case, using the $\mathrm{CP}$ method, based on the group weights and group performances.

Group weights and group performances can be determined using the following formula:

$$
\begin{aligned}
& w_{j}=\frac{1}{K} \sum_{k=1}^{K} w_{j}^{k}, \\
& x_{i j}=\frac{1}{K} \sum_{k=1}^{K} x_{i j}^{k},
\end{aligned}
$$

where $w_{j}^{k}$ denotes significance of the $j$-th criteria obtained based on the standpoints of the $k$-th respondent, $x_{i j}^{k}$ denotes performance of the $i$-th alternative in relation to the $j$-th criteria obtained from $k$-th decision maker; $i=1,2, \ldots, m ; j=1,2, \ldots, n ; k$ $=1,2, \ldots, K$.

\section{CASE STUDY - SELECTION OF \\ PRODUCTION LINES IN THE \\ METALLURGICAL INDUSTRY}

In the considered case study, the evaluation of five production lines in the metallurgy industry was carried out based on the opinions of the five domain experts.

The production lines have been evaluated from three points of view:

- reliability, reflected in time and maintenance and repair costs, as well as the number of planned and unplanned downtime of the production line.

- quality of the products on these lines.

- productivity.

Therefore, the following criteria have been adopted for the purpose of evaluating production lines:

- $C_{1}$ - exploitation indicator,

- $C_{2}$ - maintenance and repair indicator,

- $C_{3}$ - performance indicator, and

- $C_{4}$ - quality indicator.

Table 1 shows the group weights obtained using the AHP method and applying formula (4), based on the standpoints of the five decision makers.

Table 1 Group weights of the evaluation criteria

\begin{tabular}{|l|c|c|c|c|c|c|}
\hline & $E_{1}$ & $E_{2}$ & $E_{3}$ & $E_{4}$ & $E_{5}$ & $w_{i}$ \\
\hline$C_{1}$ & 0.128 & 0.114 & 0.141 & 0.138 & 0.128 & 0.130 \\
\hline$C_{2}$ & 0.265 & 0.192 & 0.141 & 0.125 & 0.265 & 0.197 \\
\hline$C_{3}$ & 0.333 & 0.337 & 0.263 & 0.309 & 0.333 & 0.315 \\
\hline$C_{4}$ & 0.275 & 0.358 & 0.455 & 0.428 & 0.275 & 0.358 \\
\hline
\end{tabular}


After determining the group weights, each of the five experts have evaluated the alternatives in relation to the selected set of criteria. For evaluation the alternatives, the five-step Likert scale was used as shown in Table 2.

Table 2 Five-step Likert scale used for evaluation the performances of alternatives in relation to the set of criteria

\begin{tabular}{|c|l|}
\hline Rating & \multicolumn{1}{c|}{ Meaning } \\
\hline 5 & Excellent performances \\
\hline 4 & Good performances \\
\hline 3 & Average performances \\
\hline 2 & Below the average performances \\
\hline 1 & Bad performances \\
\hline
\end{tabular}

The performance of the alternatives obtained from the five experts are shown

in Tables 3-7.

Table 3 Performances of alternatives in relation to the criteria obtained from the first decision maker

\begin{tabular}{|c|c|c|c|c|}
\hline & $C_{1}$ & $C_{2}$ & $C_{3}$ & $C_{4}$ \\
\hline$A_{1}$ & 4 & 4 & 4 & 4 \\
\hline$A_{2}$ & 3 & 4 & 5 & 4 \\
\hline$A_{3}$ & 4 & 3 & 4 & 3 \\
\hline$A_{4}$ & 5 & 5 & 5 & 4 \\
\hline$A_{5}$ & 3 & 5 & 3 & 4 \\
\hline
\end{tabular}

Table 4 Performances of alternatives in relation to the criteria obtained from the second decision maker

\begin{tabular}{|c|c|c|c|c|}
\hline & $C_{1}$ & $C_{2}$ & $C_{3}$ & $C_{4}$ \\
\hline$A_{1}$ & 4 & 3 & 4 & 4 \\
\hline$A_{2}$ & 4 & 5 & 5 & 5 \\
\hline$A_{3}$ & 5 & 3 & 4 & 4 \\
\hline$A_{4}$ & 5 & 5 & 5 & 3 \\
\hline$A_{5}$ & 3 & 5 & 3 & 4 \\
\hline
\end{tabular}

Table 5 Performances of alternatives in relation to the criteria obtained from the third decision maker

\begin{tabular}{|c|c|c|c|c|}
\hline & $C_{1}$ & $C_{2}$ & $C_{3}$ & $C_{4}$ \\
\hline$A_{1}$ & 5 & 5 & 4 & 4 \\
\hline$A_{2}$ & 5 & 5 & 3 & 3 \\
\hline$A_{3}$ & 4 & 4 & 4 & 3 \\
\hline$A_{4}$ & 5 & 4 & 4 & 4 \\
\hline$A_{5}$ & 3 & 5 & 3 & 4 \\
\hline
\end{tabular}


Table 6 Performances of alternatives in relation to the criteria obtained from the fourth decision maker

\begin{tabular}{|c|c|c|c|c|}
\hline & $C_{1}$ & $C_{2}$ & $C_{3}$ & $C_{4}$ \\
\hline$A_{1}$ & 4 & 4 & 4 & 4 \\
\hline$A_{2}$ & 4 & 3 & 5 & 5 \\
\hline$A_{3}$ & 3 & 4 & 5 & 3 \\
\hline$A_{4}$ & 3 & 3 & 5 & 3 \\
\hline$A_{5}$ & 3 & 5 & 3 & 4 \\
\hline
\end{tabular}

Table 7 Performances of alternatives in relation to the criteria obtained from the fifth decision maker

\begin{tabular}{|c|c|c|c|c|}
\hline & $C_{1}$ & $C_{2}$ & $C_{3}$ & $C_{4}$ \\
\hline$A_{1}$ & 4 & 3 & 5 & 4 \\
\hline$A_{2}$ & 3 & 3 & 4 & 3 \\
\hline$A_{3}$ & 3 & 2 & 5 & 3 \\
\hline$A_{4}$ & 3 & 4 & 4 & 4 \\
\hline$A_{5}$ & 3 & 4 & 3 & 4 \\
\hline
\end{tabular}

Finally, the group performances, shown in Table 8. obtained applying the formula (5), are

Table 8 Group performances of alternatives obtained from five experts

\begin{tabular}{|c|c|c|c|c|}
\hline & $C_{1}$ & $C_{2}$ & $C_{3}$ & $C_{4}$ \\
\hline$A_{1}$ & 4.200 & 3.800 & 4.200 & 4.000 \\
\hline$A_{2}$ & 3.800 & 4.000 & 4.400 & 4.000 \\
\hline$A_{3}$ & 3.800 & 3.200 & 4.400 & 3.200 \\
\hline$A_{4}$ & 4.200 & 4.200 & 4.600 & 3.600 \\
\hline$A_{5}$ & 3.000 & 4.800 & 3.000 & 4.000 \\
\hline
\end{tabular}

The normalized and weighted normalized decision matrix was obtained using the following formula:

$$
\begin{aligned}
& \bar{x}_{i j}=\frac{x_{j}^{*}-x_{i j}}{x_{j}^{*}-x_{j}^{-}}, \\
& v_{i j}=w_{j} \frac{x_{j}^{*}-x_{i j}}{x_{j}^{*}-x_{j}^{-}},
\end{aligned}
$$

where $\bar{x}_{i j}$ denotes the normalized performance of the $i$-th alternative in relation to the $j$-th criteria, and $v_{i j}$ denoted the weighted normalized performance of the $i$-th alternative in relation to the $j$-th criteria.

The normalized and weighted normalized decision matrix are shown in Tables 9 and 10 .

Table 9 Normalized decision making matrix

\begin{tabular}{|c|c|c|c|c|}
\hline & $C_{1}$ & $C_{2}$ & $C_{3}$ & $C_{4}$ \\
\hline$A_{1}$ & 0.0000 & 0.6250 & 0.2500 & 0.0000 \\
\hline$A_{2}$ & 0.3333 & 0.5000 & 0.1250 & 0.0000 \\
\hline$A_{3}$ & 0.3333 & 1.0000 & 0.1250 & 1.0000 \\
\hline$A_{4}$ & 0.0000 & 0.3750 & 0.0000 & 0.5000 \\
\hline$A_{5}$ & 1.0000 & 0.0000 & 1.0000 & 0.0000 \\
\hline
\end{tabular}


Table 10 Weighted normalized decision making matrix

\begin{tabular}{|c|c|c|c|c|}
\hline & $C_{1}$ & $C_{2}$ & $C_{3}$ & $C_{4}$ \\
\hline$A_{1}$ & 0.0000 & 0.1233 & 0.0787 & 0.0000 \\
\hline$A_{2}$ & 0.0433 & 0.0986 & 0.0393 & 0.0000 \\
\hline$A_{3}$ & 0.0433 & 0.1972 & 0.0393 & 0.3583 \\
\hline$A_{4}$ & 0.0000 & 0.0740 & 0.0000 & 0.1791 \\
\hline$A_{5}$ & 0.1298 & 0.0000 & 0.3147 & 0.0000 \\
\hline
\end{tabular}

Overall performances of alternatives, as $\quad p=1$, are shown in Table 11. well as rank of alternatives, for parameter

Table 11 Overall performances of alternatives, for parameter $p=1$

\begin{tabular}{|c|c|c|}
\hline Alternatives & $L_{1, i}$ & Rank \\
\hline$A_{1}$ & 0.2019 & 2 \\
\hline$A_{2}$ & 0.1812 & 1 \\
\hline$A_{3}$ & 0.6381 & 5 \\
\hline$A_{4}$ & 0.2531 & 3 \\
\hline$A_{5}$ & 0.4445 & 4 \\
\hline
\end{tabular}

As shown in Table 11, the most acceptable alternative is an alternative, i.e. production line designated as $A_{2}$.
The overall performances of alternatives, as well as the rank of alternatives, for parameter $p=5$, are shown in Table 12 .

Table 12 Overall performances of alternatives, for parameter $p=5$

\begin{tabular}{|c|c|c|}
\hline Alternatives & $L_{5, i}$ & Rank \\
\hline$A_{1}$ & 0.00003 & 2 \\
\hline$A_{2}$ & 0.00001 & 1 \\
\hline$A_{3}$ & 0.00620 & 5 \\
\hline$A_{4}$ & 0.00019 & 3 \\
\hline$A_{5}$ & 0.00312 & 4 \\
\hline
\end{tabular}

\section{CONCLUSIONS}

Based on the data from Table 12, it can be concluded that the increase of parameter $p$ does not affect the ranking of alternatives, which is why the production line designated as $A_{2}$ can be considered the most appropriate under the given conditions.
In modern business, often are used different methods and algorithms in order to solve the complex problems that accompany the production and optimization of production factors, which have an impact on profitability. The complexity of the problem 
often requires the application of decision making methods in order to solve the mentioned problems.

Every organization today faces the problem of decision-making. In this sense, one of the intentions of this paper was to present a model based on the multi-criteria decision making methods, which aims to solve problem of selecting the optimal production lines in the metallurgical industry.

The proposed model represents a hybrid AHP-CP model that was tested on a case study for the selection of production lines in the metallurgical industry. Applying this approach, the most acceptable production line was successfully selected. It was also found that an increase in the value of parameter $p$ does not affect the ranking order of the alternatives, which makes the production line designated as $A_{2}$ as the most appropriate under the given conditions. Previously stated shows that the proposed model is applicable and effective, especially as it can help the management in a selection of strategies in order to optimize the allocation of available resources.

\section{REFERENCES}

[1] Legrand A. C., Suzeau P., Renier E., Truchetet F., Gorria P., Meriaudeau F., Machine Vision Systems in the Metallurgy Industry. Journal of Electronic Imaging, 10(1) (2001) 274-283.

[2] Vujić D., Stanujkić D., Urošević S., Karabašević D., An Approach to Leader Selection in the Mining Industry Based on the Use of Weighted Sum Preferred Levels of the Performances Method. Mining and Metallurgy Engineering Bor, (4) (2016), 53-62.

[3] Mardani A., Jusoh A., MD Nor K., Khalifah Z., Zakwan N. Valipour A., Multiple Criteria Decision-Making
Techniques and Their Applications-A Review of Literature from 2000 to 2014. Economic Research, 28(1) (2015) 516-571.

[4] Turskis Z. Zavadskas E. K., Multiple Criteria Decision Making (MCDM) Methods in Economics: An Overview. Technological and Economic Development of Economy, 2 (2011) 397-427.

[5] Ishak N. M., Sivakumar D., Mansor M. R., Thermoplastic Matrix Selection for Fibre Metal Laminate Using Fuzzy Vikor and Entropy Measure for Objective Weighting. Journal of Engineering Science and Technology, 12(10) (2017) 2792-2804.

[6] Huang C. Y., Hung M. C., Jhu T. L., Tzeng, G. H., Selecting a CMOS sensor by using a fuzzy MCDM framework. In System Science and Engineering (ICSSE), 2010 International Conference (pp. 119-123). IEEE.

[7] Saaty T.L., The Analytical Hierarchy Process: Planning, Priority Setting, Resource Allocation. McGraw-Hill, New York, 1980.

[8] Yu P. L., A Class of Solutions for Group Decision Problems. Management Science 19(8) (1973) 936-946.

[9] Zeleny M., Compromise programming. In: Multiple Criteria Decision Making, eds: J. Cochrane L. \& M. Zeleny, pp. 262-301, University of South Carolina Press, Columbia, SC, 1973.

[10] Khodaei H., Hajiali M., Darvishan A., Sepehr M., Ghadimi, N., Fuzzy-Based Heat and Power Hub Models for CostEmission Operation of an Industrial Consumer Using Compromise Programming. Applied Thermal Engineering, 137 (2018) 395-405.

[11] Ekhtiari M., Zandieh M., Alem-Tabriz A., Rabieh, M., A Nadir Compromise Programming for Supplier Selection 
Problem under Uncertainty. International Journal of Industrial Engineering \& Production Research, 29(1) (2018) 1-14.

[12] Salas-Molina F., Pla-Santamaria D., Rodríguez-Aguilar, J. A., Empowering Cash Managers Through Compromise Programming. In Financial Decision
Aid Using Multiple Criteria (pp. 149173). Springer, Cham, 2018.

[13] Tecle A., Shrestha B. P., Duckstein, L., A Multi-Objective Decision Support System for Multi-Resource Forest Management. Group Decision and Negotiation, 7(1) (1998) 23-40. 